\title{
sciendo
}

10.2478/AMB-2020-0018

\section{CLINICAL AND EPIDEMIOLOGICAL STUDY OF SUPERNUMERARY TEETH IN PATIENTS FROM PLOVDIV REGION}

\author{
R. Cholakova \\ Department of Oral Surgery, Faculty of Dental Medicine, Medical University - Plovdiv, Bulgaria
}

\begin{abstract}
Abnormalities in the number of teeth are conditions that occur predominantly in childhood. Therefore, monitoring the prevalence and early diagnosis is very important for the timely and appropriate therapeutic approach. The aim of the study was to investigate the incidence of supernumerary teeth in patients from the city of Plovdiv. Methods and equipment: 1,000 dental patients were studied. Data were collected from patients seeking medical attention at the Faculty of Dental Medicine in Plovdiv. We used clinical, X-ray and statistical methods for investigation. Results: A 1.1\% prevalence of supernumerary teeth (ST) was observed in the studied patients. A statistically significant difference was found between the presence of ST in the permanent and mixed dentition, with a $3 \%$ relative proportion of ST in the mixed and $0.62 \%$ in the permanent dentition $(p<0.05)$. The relative proportion of ST in the maxilla was $90.9 \%$, and in the mandible $-9.1 \%$. A statistically significant difference $(p<0.05)$ was found in the distribution of ST by jaws. In our study, a higher frequency of mesiodens and distomolar (1.08\% and $0.22 \%$, respectively) was found in males, and a decreasing relative proportion from the midline to distally in females (mesiodens $-0.56 \%$, paramolar $-0.19 \%$, distomolar $-0.19 \%)$. Conclusion: Supernumerary teeth are a relatively rare dental abnormality in the Bulgarian population. Its distribution by sex and morphology corresponds to the prevalence in Caucasians and populations of southern countries.
\end{abstract}

Key words: supernumerary teeth, frequency, distribution by sex, dentition, mesiodens, paramolar, distomolar, parapremolar

Corresponding author: Radka Cholakova, Department of Oral Surgery, Faculty of Dental Medicine, Medical University, 3 Hr. Botev blvd., 4000 Plovdiv, Bulgaria, e-mail: r_cholakova1978@abv.bg

\section{INTRODUCTION}

upernumerary teeth (ST) or hyperdontia is defined as presence of additional teeth or odontogenic structures formed from the tooth germ in excess of the normal dental formula, i.e. 20 deciduous and 32 permanent teeth, regardless of their location and shape. The term "supplemental teeth" was introduced more than a century ago by Tomes
(1873), and it means teeth with morphology similar to that of teeth of the normal dentition [1].

Abnormalities in the number of teeth are conditions that occur predominantly in childhood. Therefore, early diagnosis is very important for the appropriate therapeutic approach. The higher frequency of diagnosing this abnormality in recent years can be associated with the greater attention paid by pediatricians and dental 
practitioners. For a timely therapeutic approach, it is necessary to monitor the prevalence in the population. In a literature study, we found no data on the epidemiology of ST in patients from the city of Plovdiv.

\section{OBJECTIVE}

The objective was to carry out a clinical and epidemiological study of supernumerary teeth in patients from the city of Plovdiv. One thousand $(1,000)$ dental patients were studied. Inclusion and exclusion criteria are listed in table 1.

Table 1. Eligibility criteria

\begin{tabular}{|l|l|}
\hline \multicolumn{1}{|c|}{ Inclusion criteria: } & \multicolumn{1}{c|}{ Exclusion criteria: } \\
\hline $\begin{array}{l}\text { 1. Patients in the age range } \\
4 \text { to } 74, \text { in relation to the } \\
\text { WHO's definition of old age } \\
\text { - 74 years of age [2]. }\end{array}$ & $\begin{array}{l}\text { 1. Radiographs of inadequate } \\
\text { quality }\end{array}$ \\
$\begin{array}{l}\text { 2. Oncomplete test results } \\
\text { available }\end{array}$ & $\begin{array}{l}\text { 3. Patient's refusal to partici- } \\
\text { pate in the study }\end{array}$ \\
\hline
\end{tabular}

\section{METHODS AND EQUIPMENT}

Data were collected from patients seeking medical attention at the Faculty of Dental Medicine in Plovdiv. The participants in the study were divided into seven age groups: 4 10; 11 20; 21 30; 31 40; 41 50; 51 60; over 61 years of age.

1. Clinical methods: Each patient was subjected to a clinical examination and a case report card was filled out. Erupted supernumerary teeth were detected and described according to their location in the jaw bone: (1) mesiodens - in the palatal midline; (2) parapremolar - in the premolar region; (3) distomolar - a fourth permanent molar located either directly distal or distolingual to the third molar; (4) paramolar - in the interproximal space buccal or lingual to the upper second and third molars [3]; (5) other - depending on the tooth next to which they were located [4].

2. X-ray methods: An orthopantomography (OPTG) by using Planmeca Promax Classic was performed for each patient, with an exposure time of 10 seconds, $66 \mathrm{kV}, 9 \mathrm{~mA}$ for the adults and an exposure time of 13.2 seconds, 66 $\mathrm{kV}, 9 \mathrm{~mA}$ for the children.

3. Statistical methods: Statistical data processing was performed by using the SPSS (for Windows). The level of significance was set at $p<$ 0.05 . Charts were created by graphical analysis using the Microsoft Excel 2016.

\section{RESULTS}

One thousand $(1,000)$ patients were examined in a period of one calendar year at the Department of Oral Surgery and the Department of Pediatric Dental Medicine of the Faculty of Dental Medicine at the Medical University of Plovdiv (Table 2).

Table 2. Characteristics of the patients studied

\begin{tabular}{|l|c|c|c|}
\hline Characteristics & \multicolumn{3}{|c|}{ mean \pm SE } \\
\hline Age (years) & \multicolumn{3}{|c|}{$31.527 \pm 16.954$} \\
Minimum & \multicolumn{3}{|c|}{4} \\
Maximum & \multicolumn{3}{|c|}{72} \\
Male & \multicolumn{3}{|c|}{$30.48 \pm 0.809$} \\
Female & \multicolumn{3}{|c|}{$32.41 \pm 0.713$} \\
\hline & Number & $\%$ & Sp \\
\hline Sex & & & \\
Male & 461 & 46.1 & $1.58 \%$ \\
Female & 539 & 53.9 & $1.58 \%$ \\
\hline Total & 1,000 & 100 & \\
\hline
\end{tabular}

The mean age of the patients was 31.527 years, with the youngest being 4 , and the oldest -72 . The relative share of female and male patients was $53.9 \%$ and $46.1 \%$, respectively. The mean age of male and female patients was $30.486 \pm 17.37$ years and 32.417 \pm 16.55 years, respectively.

The analysis of the frequency distribution of the studied patients by age groups showed that most of them were in their third decade, followed by the fifth and the fourth decades. No statistically significant difference in the distribution by age groups was found between the two sexes (Pearson Chi-Square $=0.044$; $p>0.05)$ (Fig. 1).

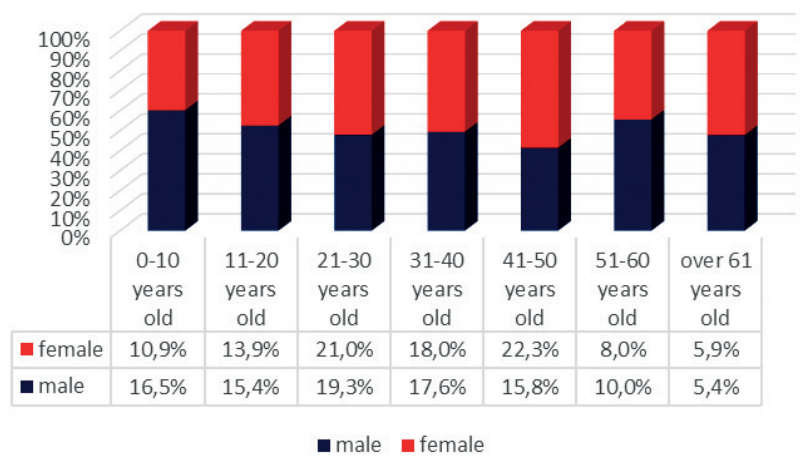

Fig. 1. Distribution of patients of age groups

The majority of the patients $(79.8 \%)$ had permanent dentition, followed by those with mixed dentition $(19.7 \%)$, and the lowest was the number of the patients with primary dentition $(0.5 \%)$. 
A statistically significant difference was found between the presence of ST in the permanent and mixed dentition, with a $3 \%$ relative proportion of ST in the mixed and $0.62 \%$ in the permanent dentition (Fisher's exact test $=0.024 ; p<0.05$ ). The relative proportion of ST was greatest in the age group 40 to 10 , followed by the age group of over 61 , the fourth and the second decade, which was deemed statistically significant (Fisher's exact test $=0.002, p<0.05$ ) (Fig. 2).

The occurrence of supernumerary teeth was assessed as being $1.1-1.3 \%$ for the male and $0.9 \%$ for the female studied patients. No statistically significant difference between sexes was found for the presence of ST (Pearson Chi-square $=0.572 ; p>0.05$ ).

The relative proportion of ST was $90.9 \%$ for the maxilla and $9.1 \%$ for the mandible (Table 3 ). A statistically significant difference $(p<0.05)$ was found in the distribution of ST by jaws.

Table 3. Distribution of the diagnosed ST by jaws

\begin{tabular}{|l|c|c|c|}
\hline Location of the ST in the jaws & $\mathbf{N}$ & $\%$ & Sp \\
\hline Maxilla & 10 & $90.9 \%$ & $8.62 \%$ \\
\hline Mandible & 1 & $9.1 \%$ & $8.62 \%$ \\
\hline Total & 11 & $100 \%$ & \\
\hline
\end{tabular}

A larger relative proportion of mesiodens and distomolar was found in the male patients, while in the female patients, ST were distributed in decreasing order from medial to distal (Fig. 3).

\section{DISCUSSION}

Finding the prevalence of dental abnormalities is important for dental practitioners, anthropologists and other healthcare professionals. There are significant differences between some epidemiological studies. Finding prevalence is difficult due to differences resulting from variations in demographic and environ- mental factors. We found that the prevalence of ST was $1.1 \%$. The same prevalence was reported by Syriac et al. [5]. Hyperdontia prevalence in the general population is between $0.09-0.29 \%$, and according to other authors, it reaches $1.53-1.57 \%[1,3,4$, 7]. Alberti et al. [8] found an incidence of $0.38 \%$ in the age between 6 and 10 years, with a significant increase in the relative proportion in the 9-year-olds (0.64-1.06\%). We found an incidence of $4.44 \%$ in the patients aged 4-10 years. B. Backman, Y.B Wahlin found hyperdontia prevalence of up to $1.9 \%$ in 7 -yearold children in Sweden [9]. Koch et al. [10] found a ST prevalence of $1-3 \%$ in the permanent dentition, and according to Rajab Hamdam [11], the prevalence was $0.1-3.8 \%$ in the permanent dentition and $0.3-0.8 \%$ in the primary dentition $[3,12,13]$. Gopakumar D et al. [12] reported $0.39 \%$ prevalence in patients in India. Öztas B et al. [4] found $1.6 \%$ ST prevalence in patients aged 13-70. Leco-Berrocal et al. [14] reported a ST prevalence of $1.05 \%$ in individuals aged $7-34$ in Madrid. The reported incidence in the Mexican population was $3.2 \%$ in individuals aged 2-55 [15]. The observed deviations in hyperdontia prevalence are due to age differences in the studied patient groups.

According to other authors, the relative proportion of $\mathrm{ST}$ in the permanent dentition of different populations was $0.5-5.3 \%[3,16]$. Tumen et al. [17] found a prevalence of $1.45 \%$ in outpatient Turkish population aged 12-25. Esenlik et al. [18] reported $2.3 \%$ incidence of ST in the permanent dentition of the Turkish population; however, no distomolars were found as the study was carried out in younger individuals (age group 6-16 years) and distomolar formation occurs later.

Supernumerary teeth are more common in the permanent $(0.5-3.8 \%)$ than in the primary dentition [1, $3,9-24]$. The great difference between the two dentitions, in terms of the incidence of supernumerary teeth, is probably due to the fact that hyperdontia in the primary dentition remains unnoticed by the parents as it does not cause any other abnormalities [23]. In primary dentition, a maxillary lateral incisor is

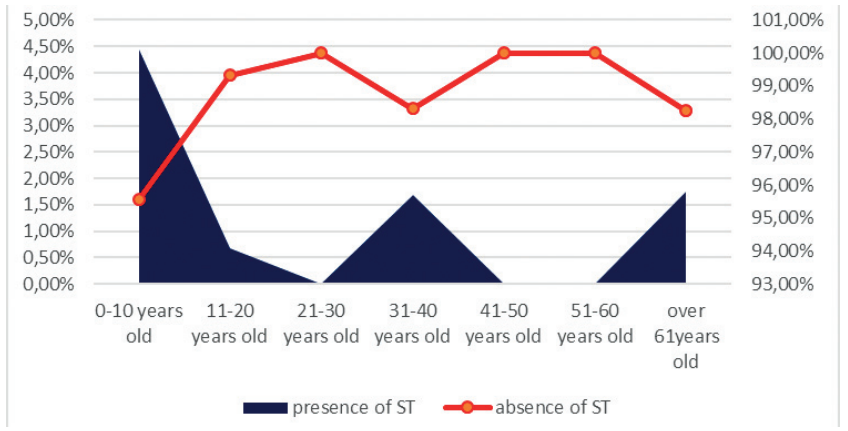

Fig. 2. Distribution of the diagnosed ST by age group

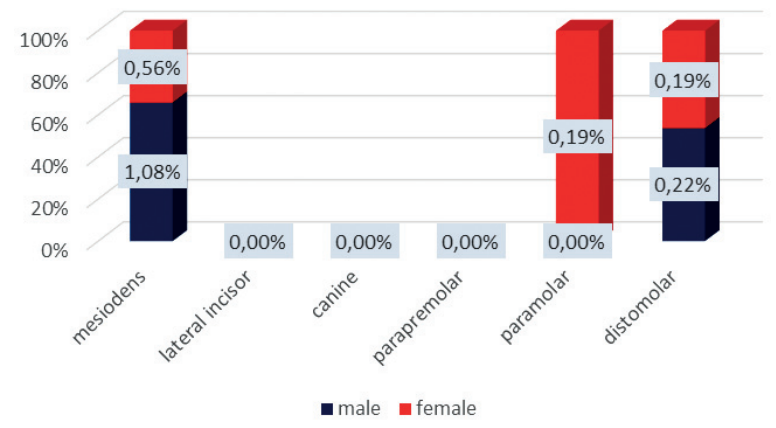

Fig. 3. Distribution of ST by sex 
most common, followed by maxillary and mandibular canines, unlike permanent dentition [24]. In our study, the most common type of ST was mesiodens (72.72\%), followed by distomolar $(27.27 \%)$ and paramolar (18.18\%). Most of the "supplemental teeth" in the primary dentition are conical or eumorphic, and usually this abnormality remains unnoticed as the supernumerary teeth erupt at normal time, have normal morphology and correct position and, also, they may be confused with fusion or gemination [1, 24, 25].

Supernumerary teeth are found more frequently in males than in females, in a 2:1 ratio for the permanent dentition, although according to some authors the ratio varies from $1.7: 1$ to $4.5: 1[3,4,8,11,19$ 22, 24, 25]. According to Öztaş [4], the ratio in the Turkish population is $1.2: 1$, and according to Celikoglu et al. [6] it is 1.8:1, whereas no significant differences were found in the primary dentition. We found a ratio of 1.2:1 in favour of the males, the same as Öztaş. Contrary to most authors, Clayton, Bäckman and Wahlin reported higher proportion of supernumerary teeth in females [19]. Subphenotypes of supernumerary teeth are differently distributed in both sexes - they are more common in the midline and in the premolar region in males, but in females, the incisors and canines are more common [19]. In our study, a higher incidence of mesiodens and distomolar $(1.08 \%$ and $0.22 \%$, respectively) was found in males, and a decreasing relative proportion from the midline to distally in females (mesiodens $-0.56 \%$, paramolar $-0.19 \%$, distomolar $-0.19 \%$ ).

Some authors found that 67 to $77.5 \%$ of the cases of hyperdontia affect the maxilla $[20,26]$, and, according to others, both jaws are equally affected [27], with $97.5 \%$ of the supernumerary teeth being in the incisor region $[7,8,20,22,28]$. Our results show predominant involvement of the maxilla $(90.9 \%)$, with the incisor region being affected in $72.72 \%$ of the cases.

The relative proportion of mesiodens is $47-67 \%$, with prevalence in the general population of 0.15 to $1.9 \%[3,8,28,29]$. We found a mesiodens incidence of $0.8 \%$ in the general population. A recent Indian study reported a higher prevalence rate of $3.18 \%$, showing either an increase in the incidence or ethnic variability [29].

Distolomars are the next in incidence and represent $26 \%$ of the supernumerary teeth, found in $0.13-0.6 \%$ [3], and according to Arslan - in $0.57 \%$ of the general population [26]. In our study, the proportion of distomolars was $27.27 \%$, and their prevalence in the general population was $0.3 \%$.

Paramolars are in the range between 3 and $9 \%$ of all supernumerary teeth and their incidence is in the range from 0.29 to $0.64 \%$ [30]. We found a proportion of paramolars of $18.18 \%$ and prevalence in the general population of $0.2 \%$.

Parapremolars were found to be about $10 \%$ of all supernumerary teeth, with $75 \%$ of them in the mandible $[25,31]$.

\section{CONCLUSIONS}

Supernumerary teeth are a relatively rare dental abnormality in the Bulgarian population. Its distribution by sex and morphology corresponds to the prevalence in Caucasians and populations of southern countries. Our study confirmed the finding of other authors that supernumerary teeth occur more frequently in the maxilla, probably due to its more complex embryonic development and the deviations that may occur in this process. Supernumerary teeth are most common in the premaxilla.

\section{Conflicts of interest}

The author declare no conflicts of interest.

\section{REFERENCES}

1. Anil P. Management of Supplemental Permanent Maxillary Lateral Incisor: A Rare Case. IOSR Journal of Dental and Medical Sciences (JDMS). 2012;1(6),24-26.

2. Dokova K. Research in oral health: basic methods. 5-th Edition, Medical University - Varna, 2017, 19-21 (book in Bulgarian).

3. Fernandez Montenegro P, Valmaseda Castellon E, Berini Aytes L, Gay Escoda C. Retrospective study of 145 supernumerary teeth. Med Oral Patol Oral Cir Bucal. 2006;11(4):E339-44.

4. Öztas B, Bardak C, Şebnem Kursun E, Akbulut N. Clinical characteristics of non-syndromic supernumerary teeth in a cohort of Turkish patients. Oral Radiol 2011;27:108-113.

5. Syriac G, Joseph E, Rupesh S, Philip J, Cherian SA, Mathew J. Prevalence, characteristics, and complications of supernumerary teeth in nonsyndromic pediatric population of South India: A clinical and radiographic study. J Pharm Bioall Sci 2017;9:231-236.

6. Celikoglu M, Kamak H, Oktay H. Prevalence and characteristics of supernumerary teeth in a non-syndrome Turkish population: associated pathologies and proposed treatment. Med Oral Patol Oral Cir Bucal. 2010;15(4):e575-8.

7. Gabris K, Fabian G, Kaan M, Rozsa N, Tarjan I. Prevalence of hypodontia and hyperdontia in paedodontic and orthodontic patients in Budapest. Community Dent Health. 2006;23(2):80-2.

8. Alberti G, Mondani PM, Parodi V. Eruption of supernumerary permanent teeth in a sample of urban primary school population in Genoa, Italy. Eur J Paediatr Dent. 2006;7(2):89-92.

9. Backman B, Wahlin YB. Variations in number and morphology of permanent teeth in 7-year-old Swedish children. Int J Paediatr Dent. 2001;11(1):11-7.

10. Koch H, Schwartz O, Klausen B. Indications for surgical removal of supernumerary teeth in the premaxilla. Int $\mathrm{J}$ Oral Maxillofac Surg. 1986;15(3):273-81. 
11. Rajab LD, Hamdan MA. Supernumerary teeth: review of the literature and a survey of 152 cases. Int J Paediatr Dent. 2002;12(4):244-54.

12. Gopakumar D, Thomas J, Ranimol P, Vineet DA,Thomas $S$, Nair VV. Prevalence of supernumerary teeth in permanent dentition among patients attending a dental college in South Kerala: A pilot study. J Indian Acad Oral Med Radiol 2014;26:42-5.

13. Valmaseda-Castellon E, Berini-Aytes L, Gay-Escoda C. Supernumerary premolars. Report of 10 cases. Bull Group Int Rech Sci Stomatol Odontol. 2001;43(1):19-25.

14. Leco-Berrocal MI, Martín-Morales JF, Martínez-González JM. An observational study of the frequency of supernumerary teeth in a population of 2000 patients. Med Oral Patol Oral Cir Bucal 2007;12:E134-8. @ Medicina Oral S. L. C.I.F. B 96689336 - ISSN 1698-6946

15. Salcido-Garcia JF, Ledesma - Montes C, Hernandez-Florez F, Perez D, Garces- Ortez M. Frequency of supernumerary teeth in Mexican population. Med Oral Patol Oral Cir Bucal 2004;9:403-9.

16. Solares R, Romero MI. Supernumerary premolars: a literature review. Pediatr Dent. 2004;26(5):450-8.

17. Tumen EC, Yavuz I, Tumen DS, Hamamci N, Berber G, Atakul F, Uysal E. The Detailed Evaluation of Supernumerary Teeth with the Aid of Cone Beam Computed Tomography, Biotechnology \& Biotechnological Equipment, 2010;24:2, 1886-1892, DOI: $10.2478 / \mathrm{N} 10133-010-0023-5$

18. Esenlik E, Sayin MO, Atilla AO, Ozen T, Altun C, Başak F. Supernumerary teeth in a Turkish population. Am J Orthod Dentofacial Orthop. 2009;136:848-52.

19. Mallineni SK. Supernumerary teeth: review of the literature with recent updates. Hindawi Publishing Corporation. Conference Papers in Science, Volume 2014, Article ID 764050 , 6 pages

20. Ata-Ali $F$, Ata-Ali J, Peñarrocha-Oltra $D$, Peñarrocha-Diago M. Prevalence, etiology, diagnosis, treatment and complications of supernumerary teeth. J Clin Exp Dent 2014 Oct 1;6(4):e414-8. doi: 10.4317/jced.51499. eCollection 2014 Oct. Review.

21. Nayak UA, Mathian VMV. Non-syndrome associated multiple supernumerary teeth: A report of two cases. J Indian Soc Pedod Prev Dent 2006;24:11-14.

22. Fazliah SN. Supernumerary tooth: report of a case. Archives of Orofacial Sciences 2007;2, 54-58.

23. Amarlal D, Muthu M S. Supernumerary teeth: Review of literature and decision support system. Indian J Dent Res 2013;24:117-22.

24. Cugati N, Dewi FD. Rare case of supplemental mandibular central incisor in mixed dentition period. e-Journal of Dentistry 2012;2(3).

25. Wang XP, Fan J. Molecular genetics of supernumerary tooth formation. Genesis 2011;49(4):261-77. doi: 10.1002/ dvg.20715. Epub 2011 Apr 1.

26. Arslan A, Altundal H, Ozel Em. The frequency of distomolar teeth in a population of urban Turkish adults: a retrospective study. Oral Radiology. December 2009; 25(2)118-122.

27. Alvira-González J, Gay-Escoda C. Non-syndromic multiple supernumerary teeth: meta-analysis. J Oral Pathol Med. 2012;41(5):361-6. doi: 10.1111/j.1600-0714.2011.01111.x. Epub 2011 Nov 18.

28. Russell KA, Folwarczna MA. Mesiodens-diagnosis and management of a common supernumerary tooth. J Can Dent Assoc. 2003;69(6):362-6.

29. Ayers E, Kennedy D, Wiebe C. Clinical recommendations for management of mesiodens and unerupted permanent maxillary central incisors. Eur Arch Paediatr Dent 2014;15:421-428.

30. Cho SY. Supernumerary premolars associated with dens evaginatus: report of 2 cases. J Can Dent Assoc. 2005;71(6):390-3.

31. Hyun HK, Lee SJ, Ahn BD, Lee ZH, Heo MS, Seo BM, Kim JW. Nonsyndromic multiple mandibular supernumerary premolars. J Oral Maxillofac Surg. 2008;66(7):1366-9.

Received 01.07.2019 - Accepted 10.07.2019 